Article

\title{
Improving Water Access and Health through Rainwater Harvesting: Perceptions of an Indigenous Community in Jalisco, Mexico
}

\author{
Shiara K. González-Padrón ${ }^{1}$, Amy M. Lerner ${ }^{2, *}$ and Marisa Mazari-Hiriart ${ }^{2}$ \\ 1 Posgrado en Ciencias de la Sostenibilidad, Universidad Nacional Autónoma de México, \\ Mexico City 04510, Mexico \\ 2 Laboratorio Nacional de Ciencias de la Sostenibilidad, Instituto de Ecología, \\ Universidad Nacional Autónoma de México, (LANCIS-IE-UNAM), Mexico City 04510, Mexico \\ * Correspondence: amy.lerner@iecologia.unam.mx
}

Received: 20 July 2019; Accepted: 26 August 2019; Published: 6 September 2019

\begin{abstract}
This article presents a mixed methods case study of an isolated indigenous community (the Wixaritari) in Jalisco state, Mexico, where the patterns of access to water have been changing due to Rainwater Harvesting Systems (RWHSs). The lack of water in this region is extremely precarious; women and children spend approximately one to three hours a day fetching water, and families live with less than $20 \mathrm{~L}$ per person/day. To better understand the relationship between water access and health derived from the use of RWHSs, we first analyzed epidemiological data (2014-2017) from cases of Acute Diarrheal Diseases (ADDs) and household water quality. Next, we surveyed households on water access after the introduction of RWHSs, including questions about perceptions of health problems associated with water. The results revealed that the introduction of RWHSs water access in this community has increased quantitatively and qualitatively and the incidence of ADDs has decreased significantly. However, the surveys and interviews indicate a disconnect between the incidence of ADDs and perceptions of health problems. We conclude that RWHSs can have tangible benefits, but they can be potentially undermined by perceptions of communities that have different understandings of the cause of disease.
\end{abstract}

Keywords: water quality; health; indigenous community; rainwater harvesting systems; sustainable development; Mexico

\section{Introduction}

The United Nations (U.N.) General Assembly and the Human Rights Council recognized the human right to water in 2010 [1]. The sixth objective of the Sustainable Development Goals (SDG 6) proposed by the United Nations is to ensure access to water and sanitation for all [2], which will be a challenge for many countries throughout the world, including those in Latin America. Although several Latin American countries have made advances regarding the percentage of people with access to water, there are still 77 million residents without a water connection in their homes, 51 million of whom live in rural areas [3]. In Mexico, approximately 10 million inhabitants live without access to safe drinking water and those communities most affected by water scarcity are often rural and indigenous [4].

Water scarcity occurs when water demand exceeds water availability, temporally and/or spatially [5,6]. In times of such scarcity, people need to spend more time obtaining water, thus constraining their domestic or productive activities. There are several factors that drive water scarcity, including environmental (land-use/land-cover change or climatic shifts) and socioeconomic (population and economic growth or structural changes that can affect water distribution) factors $[7,8]$. In isolated 
rural communities of the Global South, the combination of environmental and socioeconomic factors produces a greater level of stress. A lack of formal institutional governance makes distribution of the vital liquid impossible in some contexts. Scarcity of water can lead to negative health outcomes such as gastrointestinal disease $[9,10]$ and infant and child mortality [11]. Solving the water scarcity situation may positively impact reducing disease, improving health and well-being, particularly in rural communities.

One specific way to alleviate the lack of access to water is through the use of rainwater, especially in rural areas. Rainwater Harvesting Systems (RWHSs) are probably the most ancient practice used in the world to cope with water supply needs. In recent decades, as a result of new technological possibilities, many countries are supporting the implementation of modern systems to address the increase in water demand pressures associated with climatic, environmental, and societal changes [12]. Although rainwater is recognized as a potential source for water use and consumption, the health impacts (positively or not) of consuming rainwater are not fully understood. Many factors are related to the health of human populations that use rainwater as a source of drinking water in rural and urban contexts $[13,14]$ and few studies have been conducted to assess changes in health associated with the consumption of rainwater, especially in Latin America [14-16]. In Mexico, for example, there has been little investigation of the impact of RWHSs, including in rural, indigenous communities such as the one highlighted in this article.

In this paper, we describe the perceived and real health impacts of RWHSs in one Wixaritari community located in Northwest Mexico. In these contexts, women and children often spend on average of one to three hours a day to fetch water, and families live with less than $20 \mathrm{~L}$ of water per person per day. However, over the past four years, these conditions have been changing with the implementation of RWHSs promoted by a group of non-governmental organizations (NGOs) in a project called Ha Ta Tukari ('water, our life' in the Wixaritari language). To understand the implications of the use of rainwater harvesting systems, we present a case study of the La Laguna community, with data on the presence of acute diarrheal cases in different seasons from 2014 to 2017 when RWHSs were installed. We also present water quality data at the household level in two different seasons and contrast these data with the results of household-level interviews that assess residents' perception of water and health. One of our main findings is that the perceptions of health are often not correlated with the epidemiological data. Thus, despite the potential of RWHSs to improve health, households tend to have a different understanding of the impact of water quality on health, which could potentially undermine the benefits of the rainwater harvesting systems.

\section{Background}

The Wixaritari (plural Wixarika) communities are a particularly isolated indigenous group in Mexico and still retain their pre-Hispanic traditions, such as language and cosmovision [17]. They are located in the Sierra Madre Occidental, in the North of the State of Jalisco, in the Mezquitic municipality (Figure 1). The Mezquitic municipality is classified by the National Population Council (CONAPO) as one of the municipalities with the highest degree of marginalization (the Marginalization Index at the municipal level was carried out with information captured in the Survey of the National Institute of Statistics and Geography (INEGI) according to the level or intensity of nine types of deficiencies encompassed in four socioeconomic dimensions: education, housing, population distribution and monetary income) in the country and with the lowest Human Development Index (HDI) (the Human Development Index (HDI) measures an average achievement in key dimensions of human development: life expectancy, education, and income), 0.440, compared to the national HDI which is $0.774[18,19]$. Additionally, the health care situation of the Wixarika communities is one of the most precarious; the Health Index (the Health Index is calculated using life expectancy at birth expressed as an index using a minimum value of 20 years and a maximum value of 85 years.) of the Mezquitic municipality is 0.323, compared to the average in Mexico which was 0.885 in 2013. 


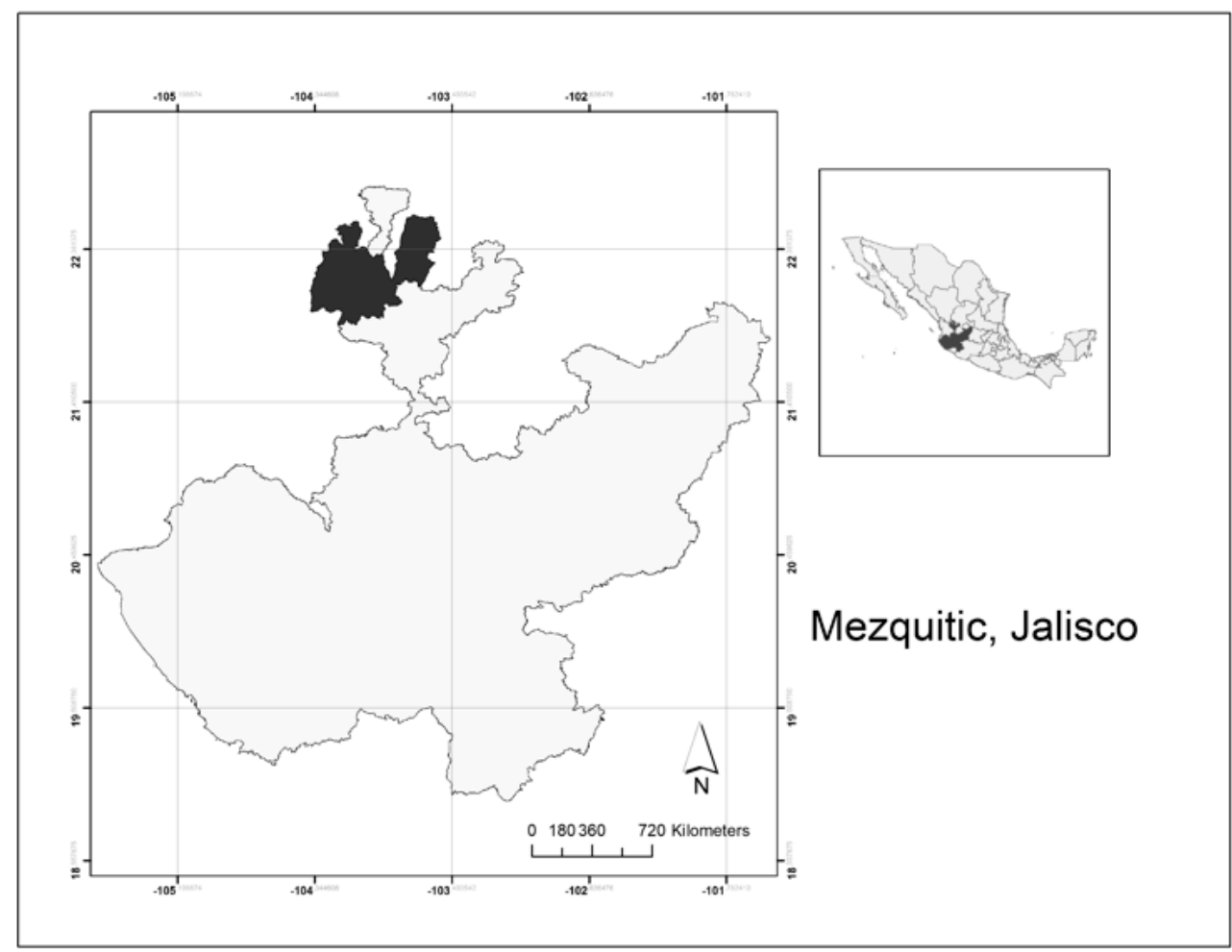

Figure 1. Map of Mezquitic municipality, Jalisco State, Mexico.

\subsection{Traditional Knowledge, Practices, and Beliefs}

The Wixaritari people have a particular way of being in the world and believe that the spirit is central, which gives them a connection to land and other elements (i.e., Peyote, deer, sun and fire). They recognize cycles and fluxes (agricultural cycles), the importance of elders, a shared sense of community and many important ceremonies. In the worldview and territoriality of the Wixarika people, there is no clear separation between the areas of nature, society and the supernatural or sacred [20]. The Wixaritari cosmos can be considered ethnocentric which everyone is a "great house", a community (kiekari). The forces or elements of nature are considered deities and are ancestors and relatives of the Wixaritari. The center of the world is located within the Wixarika territory, which reflects an anthropocentric vision and a high sense of belonging for its territory $[17,21,22]$. Water is central to the Wixarika cosmovision; due to their seasonal agriculture, many of the rituals in Wixaritari communities revolve around "making rain". Therefore, the relationship with water goes beyond a resource for daily use and is identified as the resource that gives life.

In the Wixarika political-ritual system, three or four times a year, the owners of the land or comuneros hold general assemblies that last at least four or five days and decisions must be taken unanimously. Religious festivities are even more frequent $[22,23]$. The details of these ceremonies will not be mentioned here, but they are referred to as el costumbre or the custom. El costumbre refers to "the religious-cultural expression that includes ancestral autochthonous religious elements that permeate and give meaning to the life of peoples. It is expressed in its rites, beliefs, behaviors, as well as in its social-religious organization and allows them to be in continuous communication with the sacred" [24]. The perception of health problems (gastrointestinal and respiratory disease) is diverse and ranges from a cosmological conception (el costumbre) to a Western way of thinking. For the Wixaritari, the cosmovision occupies an essential place in the legitimization of the practices and health, the state of equilibrium consists in maintaining a harmonious relationship with their deities and with their environment, which will result in 'aixi pereu erie' and 'ne kareu kuye': the feeling of well-being and being a functional (the absence of disease), the opposite to 'nereu kuye' [25]. 


\subsection{Access to Water for the Wixarika People}

The activities carried out around water are different between the rainy and dry seasons and can be classified into either seasonal activities (i.e., ritual and agricultural uses), and are activities carried out throughout the year (e.g., for drinking, cooking, and hygiene). Due to the geographical characteristics of the Sierra Madre, the end of the dry season is a critical period, when the water supply situation is very precarious due to the scarcity of natural water sources. In these communities, there are sources of water throughout the year, but the households tend to be severely water stressed: they must walk long distances (1-3 $\mathrm{h}$ a day walking) to obtain the little water that each household uses. Another way to access water is to use hoses from natural water sources when it can be channeled by gravity. The lack of water during the dry season also generates a decrease in the availability of food for breeding animals (livestock). Sometimes community members have to carry water not only for the home, but also to supply it to their animals, which have a higher risk of mortality during the dry season. The drought not only affects the water supply in the households and the community, it also has more dramatic consequences such as large forest fires.

\subsection{Sustainable Development in an Indigenous Context}

The achievement of the Sustainable Development Goals (SDG) requires the construction of a new relationship between science, policy and society that can lead to effective actions for operationalizing and implementing SDGs from local to global scales [26]. Sustainable Development Goal (SDG) 6 is essential to achieve progress in the other SDGs and vice versa. Sustainable management of water resources and sanitation supports general initiatives to end poverty and promote sustainable development [27]. In addition, the integration of different knowledge systems including indigenous and traditional knowledge represent new opportunities to be explored by sustainability science research. Johnson et al. (2016) stresses that "productive and reciprocal collaboration, co-production and co-constructions of knowledge between indigenous and sustainability sciences could create a new vision for sustaining resilient landscapes" (p. 7) [28]. Although the SDGs are presented as desirable goals for meeting human needs and interests, they do not extend to include the kinds of complexities that are identified at the local level and in indigenous cultures, such as those in Mexico [29]. This research focuses on the SDG 6 and is an example of a study were a local study case reflects a problem that exists at the global scale. Our goal is to show the need to address water scarcity by including important aspects such as culture and worldviews at the local level.

\section{Materials and Methods}

\subsection{The La Laguna Social-Ecological System Case Study}

The data collection was conducted in La Laguna, a Wixaritari community within the Mezquitic municipality, in the North of Jalisco, Mexico (Figure 1). In 2017, it had a population of 711 people in 110 households. It is approximately three hours from the main road, and five hours from the closest town Huejuquilla El Alto. The vegetation of the area consists of pine and oak forest with a cold climate (mean temperature of $15^{\circ} \mathrm{C}$ ) and the annual precipitation ranges from 800 to $1200 \mathrm{~mm} /$ year [30]. The annual rainfall regime is bimodal (two dry seasons and two rainy seasons). The main economic activities are subsistence agriculture with ancestral crops (corn, beans and squash), and artisanal activities $[20,22]$. It is one of the few communities in the region with a semi-permanent medical practice and a nurse.

The water scarcity situation began to change in 2014 with the implementation of RWHSs. The systems used were designed by Isla Urbana (https://islaurbana.org), a non-governmental organization dedicated to promoting water sustainability and RWHSs in Mexico. The systems consist of the following components: 1 . A catchment surface (usually a sheet metal roof), 2. Conveyance (the water is transported through polypropylene and/or polyvinyl chloride (PVC) pipes), 3. A stainless steel or nylon mesh filter (apertures are approximately $1 \times 2 \mathrm{~mm}$ to eliminate leaves and larger debris), 
4. First-flush units (simple mechanisms used to divert the initial precipitation during a rainfall event to wash the roof before water is allowed into the tank), 5. A cistern (made from a high-density polyethylene geomembrane contained in a galvanized steel mesh, and the cistern usually has a 14,500-L capacity), and 6. The inlet of the cistern, which has a turbulence-reducing device fitted to reduce the disturbance of sediments at the bottom of the tank by incoming water (Figure 2a). In La Laguna, the number of RWHSs increased progressively since the project was initiated in 2014, when community systems were installed in the primary school, preschool, children's dining room and health center. By 2017 , almost $100 \%$ of the homes had a RWHSs (Figure 2b).

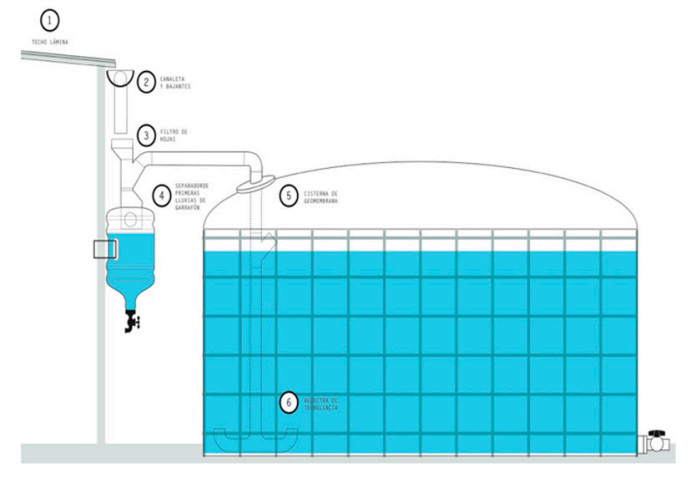

(a)

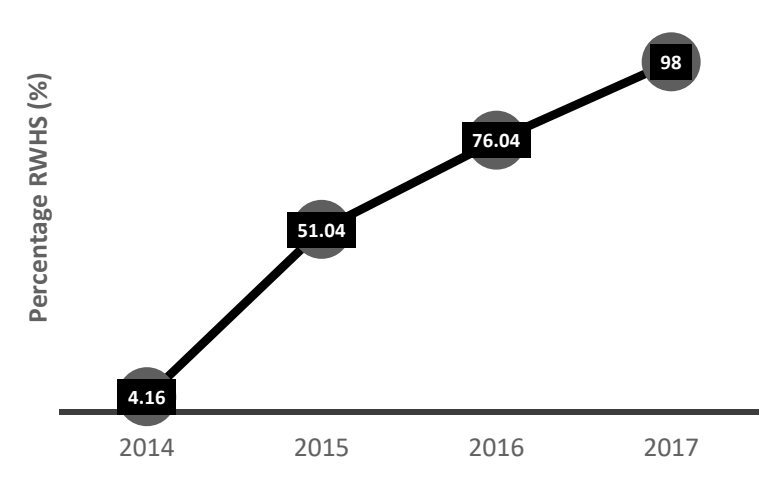

(b)

Figure 2. (a) Diagram of Rainwater Harvesting System (RWHS) features: 1. Catchment surface; 2. Conveyance; 3. Stainless steel mesh filter; 4 . First-flush units; 5 . Cistern; 6 . Turbulence-reducing device; (b) The percentage of homes with RWHSs installed in La Laguna since 2014.

\subsection{Data Collection}

The study employed a quali-quantitative mixed-method approach, including data from cases of Acute Diarrheal Diseases (ADD) from 2014 to 2017 obtained through the collaboration with the main physician in the La Laguna community. Additionally, semi-structured interviews were conducted with key actors (community authorities, and other community members), and semi-structured interviews were also conducted on water used with 26 households (representing $23 \%$ of the total households in the community). The household interviews included a tool designed to communicate across languages and allow the integration of the cultural worldview [31]. The first author spent two or three weeks in the community, three times a year from 2015 to 2018. In 2017, fieldwork was conducted for three months at the end of the dry season and the beginning of rainy season (June-August), which also included participating in the rituals (the peregrination to sacred places out of the Sierra), as a request of the religious authorities of the La Laguna community.

\subsubsection{Epidemiological Data at the Community Level}

The data sources for illnesses reported at the community level are extremely limited. The information for this study was obtained through the collaboration with the main physician in the La Laguna community, which belongs to Sanitary Region 1 Norte Colotlan. We used 227 data registries, representing those who attended medical care services and reported illnesses from January 2014 to December 2017. Weekly records included: 1. The number of patients, reason for consultation, age and gender. In order to analyze the information, the data were converted into a digital database, and identified and selected according to the principal cause of the medical visit. We selected the cases of Acute Diarrheal Diseases to analyze the trends over the 2014-2017 period. The data was reorganized to obtain the number of monthly cases because the doctor was only present in the 
community for 20 days per month. For statistical analyses, the data were grouped into four age groups: children (0-9 years old), young people (10-19), adults (20-65) and the elderly ( $\geq 65)$, and by gender.

\subsubsection{Statistical Analysis}

For the analysis of the information, databases were organized according to the frequency of diarrheal diseases reported per month from 2014 to 2017. We used general linear models (GLMs) to analyze the frequency of diseases according to years and we used age as a random factor within the years. We tested the significance of the random factor "age" and compared the complete model (model) with another model (model fixed) without the random factor and the difference in verisimilitude. To determine the best model, we used Akaike's information criterion (AIC). Adding age as a factor caused the AIC to decrease and the data was better explained. Then we replicated the same model with sex instead of age. R package version 3.1-117 was used.

\subsubsection{Semi-Structured Interviews and the Cosmo-Eco-Health Calendar}

From 2015 to 2017, 15 informal semi-structured interviews were conducted with community members, heads of household, community authorities and religious authorities in order to understand in greater depth the elements that make up the relationship that the community and its residents have with nature and specifically water. Based on participant observation and these semi-structured interviews, the instrument to be used in household interviews was developed, taking into account cultural and language barriers. Households were selected based on the representatives of all community areas, language (preferably bilingual) and accessibility (the consent of the family to participate in the interview). The interview with the heads of households were mostly with women because they are the ones responsible for providing water for the household. Twenty-six semi-structured household interviews were conducted to collect basic demographic data, such as household composition, age, gender, as well as preferred water sources, water consumption, water uses, hygienic practices and other variables such as waste disposal procedures. The interviews contained closed and open-ended questions, allowing an analysis about the perception of the relationship between water scarcity, quality (depending on the different sources), and health issues.

Nevertheless, as Spanish is not their first language (and many speak little or no Spanish), we did not want to run a typical interview alone. We therefore included the use of non-verbal methods inspired by The Ecohealth Calendar, a participatory and innovative methodological tool [31]. The household interviews included a calendar board with cards and colors. The cards were designed based on the information collected by participatory observation over the previous years related to seasonal activities, weather conditions, rituals and disease. During the interviews, we added cards to help understand the uses of different water sources. The cards were used in a circular calendar to depict how households identify different seasons, diseases, uses of water, and rituals related to water throughout the year. For example, some cards represent seasonality, exemplified by the different seasons that occur in the region, and are divided into the dry and rainy seasons with months that are dry-cold and dry-warm (Figure 3b, top row). The possibility of adding cards to each section was available in the interviews. The purpose of the calendar was to observe whether households relate disease incidence and water availability to season, or to other causes such as traditional rituals and the percentage of people using RWHSs or other sources of water. The calendar allowed for a deeper discussion about seasonality and disease that was not possible in the interviews. 


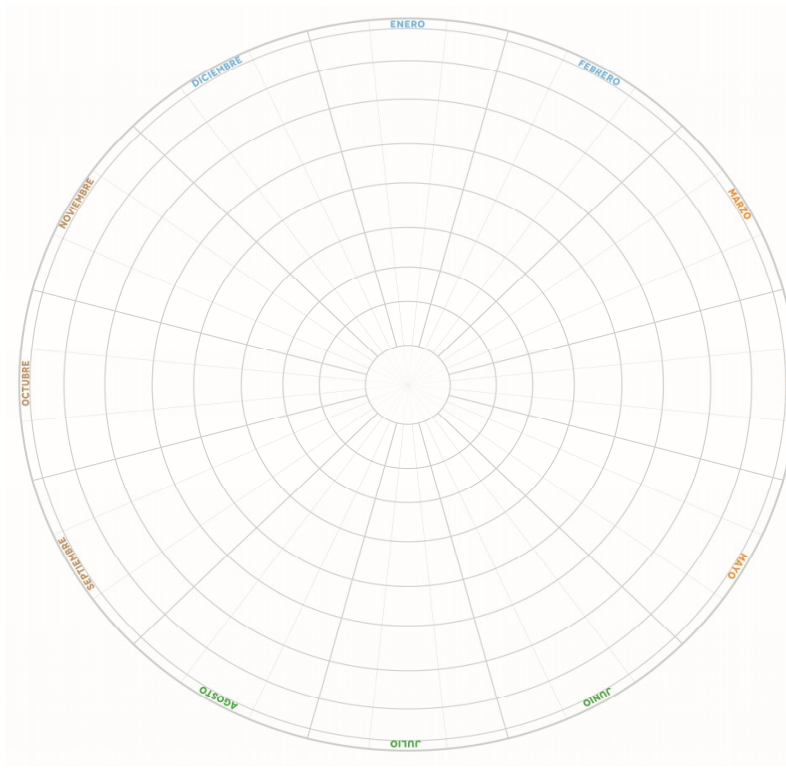

(a)

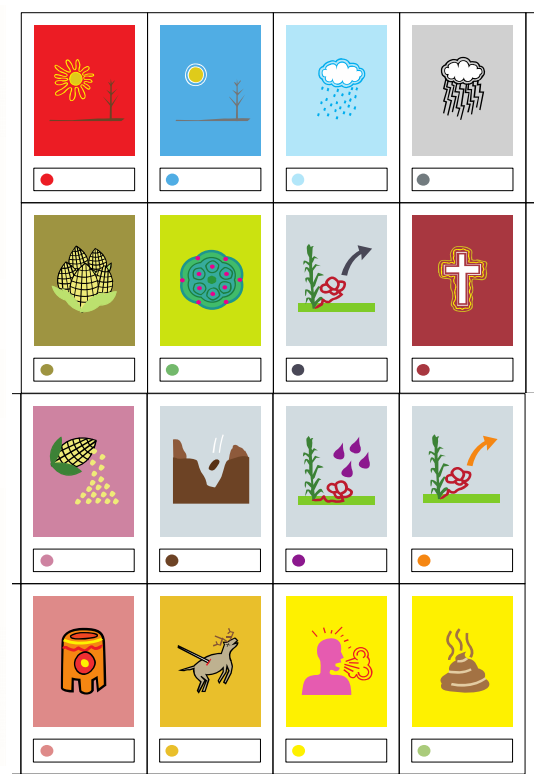

(b)

Figure 3. The cosmo-eco-health calendar: (a) The circular calendar representing the year to fill with colors according to seasonal activities, weather conditions perception, rituals, water uses and disease perception; (b) Cards depicting seasonality, rituals, water uses and disease. The top row represents different seasons, the second and third row represent the corn crop season and rituals, and the bottom row includes respiratory and diarrheal diseases.

\subsubsection{Samples of Water Quality Indicators at the Household Level}

Samples were collected from sources where users collect their drinking water. Samples were collected from two types of sources; directly from the RWHS' cistern and from storage containers in the kitchen of the household, identified as water from the RWHS or another source. All samples were collected and placed in Petrifilms (3M, St. Paul, MN) for Total Coliforms and Escherichia coli. The test was carried out in triplicate. Petrifilms were inoculated with $1 \mathrm{~mL}$ of water spread over the gel and incubated for $24 \mathrm{~h}$ at $32 \pm 2{ }^{\circ} \mathrm{C}$. Red colonies were counted as Total Coliforms and blue colonies were counted as E. coli. The results of the three tests were added and divided by three to obtain the data of each sample. In all cases, the number of colony-forming units (CFU) was normalized by the volume of water processed and multiplied by 100 to obtain a standardized total count per $100 \mathrm{~mL}$ [32].

\section{Results}

\subsection{Population Demographics of La Laguna Community}

The demographic data about the study area reported by official government statistics differ from data collected at the community medical center. In 2017, it had a population of 711 people, with a high percentage (60\%) of children and young people (between 1 and 19 years old) (Table 1), and no apparent difference between men and women. 
Table 1. Population demographic, by age group and sex, of La Laguna Community.

\begin{tabular}{cc}
\hline Age Group (Years) & Count (\%) \\
\hline $0-9$ & 36.15 \\
$10-19$ & 23.91 \\
$20-64$ & 37.69 \\
$\geq 65$ & 2.25 \\
\hline Sex & \\
\hline Male & 47.12 \\
Female & 52.88 \\
\hline
\end{tabular}

\subsection{Water Use and Management at Household Level (Rainy and Dry Season)}

For most of the year, the main water source for households comes from the RWHSs, providing water for eight to ten months, depending on the end of the dry season (usually from June to April) and the beginning of the rainy season. Households that do not have a catchment system are mainly newly installed households and because of the way in which families are organized, they are usually located near a family home with RWHSs. The sources of water were classified as rainwater catchment systems and "others", meaning springs (ojos de agua), and from "the tank", a spring that was channeled through hoses. In the household interviews, significant changes were recognized in terms of the amount of water due to the installation of RWHSs (Figure 4).

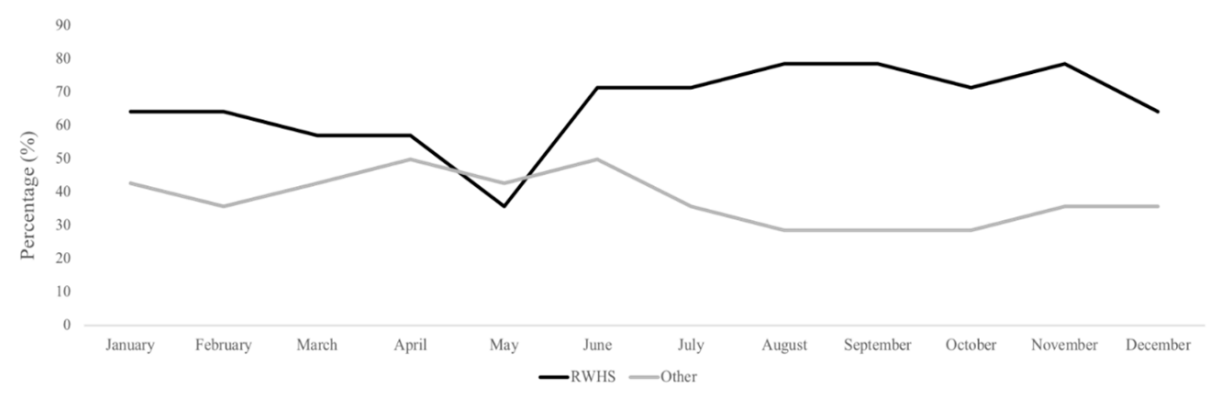

Figure 4. Percentage of households using RWHSs and other sources of water throughout the year.

As observed in Figure 4, the use of water from RWHSs is dominant throughout the year, especially during the rainy season and at the beginning of the dry season (June-December). According to the household interviews, water management is central to daily and seasonal life, and the quantity of water used in the homes is different in rainy and dry seasons, and even between the beginning and end of those seasons. In the rainy season, families with RWHSs and storage places can use their water without any restrictions. The supply during the dry season depends on the storage volume, number of members of the family and how they administer rainwater from the collection systems (i.e., using it only for drinking and cooking) (Figure 5). 




Figure 5. Water sources used at the household level during the dry and rainy season; the data was obtained from the household interviews.

During the rainy season, the water coming from the RWHSs is used broadly as compared to other sources and to the dry season (Table 2). The duration of the water during the dry months is related to water management (the amount used for drinking and cooking). The families that had more years with the RWHSs reported more months of duration and perceived better water quality than the families that recently installed the catchment system. In the interviews, it was pointed out that the rainwater was light in color and that it had no odor, in comparison with water from other sources. Rainwater is in general consumed directly without going through any filtering or disinfection process. Additionally, $76 \%$ of the families reported washing cisterns once a year before the rainy season. However, in $7 \%$ of the households, it was mentioned that they prefer the taste of the water sources they used before. Approximately $30 \%$ of the residents reported lower use of the RWHSs in the month of May, increasing the use of natural sources, due to the exhaustion of the resource (Figure 5). In most households, during the month of May, the water situation is similar to not having a system installed and women and children spend 1-3 h per day hauling water (Figure 4).

Table 2. Households and water sources.

\begin{tabular}{lc}
\hline \multicolumn{1}{c}{ Practice } & Percentage (\%) \\
\hline Using rainwater from cisterns during the rainy season & 80 \\
Using rainwater from cisterns during the dry season & 64 \\
Using rainwater and another source during the rainy season & 36 \\
Using rainwater and another source during the dry season & 40 \\
Annual cleaning frequency of cisterns & 76 \\
\hline
\end{tabular}

\subsection{Microbiological Contamination}

In the 26 samples of water for household consumption, $81 \%$ of water came from RWHSs and $19 \%$ came from water from other sources. The water obtained from RWHSs was stored in buckets in the kitchen in $26 \%$ of cases, while the remainder take water directly from the cistern. When the water came from other sources, $100 \%$ of the households stored water in tanks or buckets in the kitchen. The results on Table 3 show that RWHSs have a lower contamination rate in rainy and dry seasons. In the rainy season, the difference between RWHSs and other sources can be seen in the high level of contamination with coliforms (71.43\% from other sources in relation to $21.05 \%$ of RWHSs) and E. coli. (Table 3). Specifically, it is noteworthy that there was a high E. coli presence (>100 CFU $100 \mathrm{~mL})$ in $28.58 \%$ of samples from another source during rainy season. During the dry season, this difference is less visible with Coliforms but E. coli was absent in all the samples in RWHSs compared to $11.11 \%$ of 
samples coming from another source. Coliforms were present in RWHSs, although less of the samples tested positively than for other sources of water, especially in the rainy season.

Table 3. Water contamination with Total Coliforms and Escherichia coli for households.

\begin{tabular}{|c|c|c|c|c|}
\hline \multirow[b]{2}{*}{$\begin{array}{c}\text { Range of } \\
\text { Contamination } \\
(\mathrm{CFU} / 100 \mathrm{~mL})\end{array}$} & \multicolumn{2}{|c|}{ Rainy Season } & \multicolumn{2}{|c|}{ Dry Season } \\
\hline & $\begin{array}{l}\text { Percentage of Samples } \\
\text { with Contamination: } \\
\text { Rainwater Harvesting } \\
\text { Systems (RWHS) }\end{array}$ & $\begin{array}{l}\text { Percentage of } \\
\text { Samples with } \\
\text { Contamination: } \\
\text { Another Source }\end{array}$ & $\begin{array}{c}\text { Percentage of } \\
\text { Samples with } \\
\text { Contamination: } \\
\text { RWHS }\end{array}$ & $\begin{array}{l}\text { Percentage of } \\
\text { Samples with } \\
\text { Contamination: } \\
\text { Another Source }\end{array}$ \\
\hline \multicolumn{5}{|l|}{ Total Coliform * } \\
\hline 0 & 47.37 & 14.29 & 47.06 & 33.33 \\
\hline $1-10$ & N.D. & N.D. & N.D. & N.D. \\
\hline $11-100$ & 5.26 & N.D. & 5.88 & 11.11 \\
\hline $101-1000$ & 31.58 & 14.29 & 17.65 & N.D. \\
\hline$>1000$ & 21.05 & 71.43 & 29.41 & 55.56 \\
\hline \multicolumn{5}{|l|}{ E. coli* } \\
\hline 0 & 94.74 & 71.43 & 100 & 88.89 \\
\hline $1-10$ & 5.26 & N.D. & N.D. & 11.11 \\
\hline $11-100$ & N.D. & N.D. & N.D. & N.D. \\
\hline $101-1000$ & N.D. & 14.29 & N.D. & N.D. \\
\hline$>1000$ & N.D. & 14.29 & N.D. & N.D. \\
\hline
\end{tabular}

Note *: Any presence in water indicates contamination. None Detected (N.D.).

\subsection{The Epidemiological Data and Cases of Acute Diarrheal Diseases from 2014 to 2017}

The epidemiological data show the incidence of diseases that occurred from 2014 to 2017. The three main diseases, in order of importance, were: acute respiratory illness, acute diarrheal disease, and poison from scorpion bites. The data show a significant difference $(p<0.01)$ in the cases of gastrointestinal disease from 2014 and 2017, with the number of cases substantially decreasing over the time period (Figure 6). Specifically, there was a significant decrease in the number of cases of acute diarrheal diseases from 2014 to 2017. Figure 6a depicts the frequency of diseases as a function of age, demonstrating that those that decrease in frequency of gastrointestinal disease are children in the first category (youngest).

When the analysis was conducted with gender, there was no significant difference between females and males, despite females having more cases of diarrheal disease. The number of cases were higher between June and September, which corresponds to the end of dry season and the beginning of rainy season (see Figure $7 \mathrm{~b}$ ). 




(a)



(b)

Figure 6. Frequency of cases of acute diarrheal disease (2014-2017): (a) with age as a random factor within the years: 1. Children (0-9 years old), 2. Young people (10-19), 3. Adults (20-65), and 4 . Elders $(\geq 65)$; (b) with gender as a random factor within the years: 1 . Men and 2 . Women.

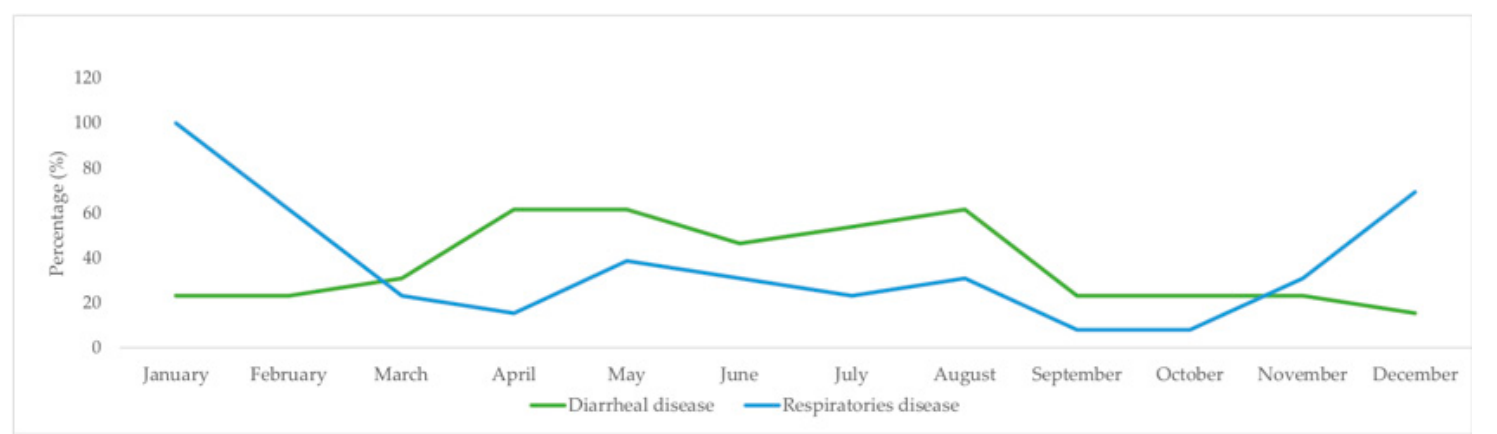

(a)

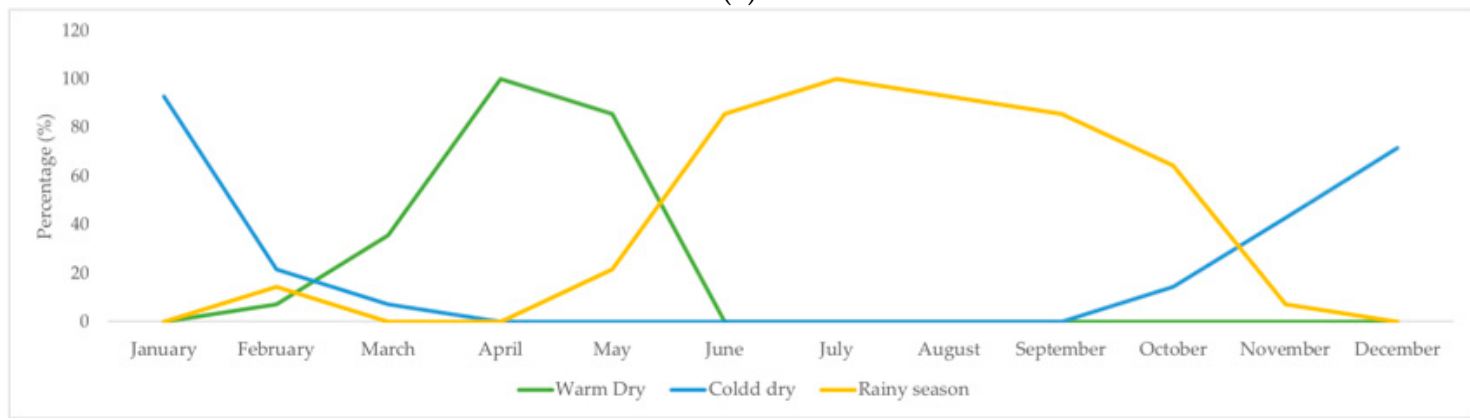

(b)

Figure 7. (a) Perceptions of diarrheal and respiratory diseases (diseases identified by month); (b) Perceptions of the seasonal changes; how household inhabitants identify the season by month.

\subsection{Health Perceptions at the Household Level}

\subsubsection{Disease Incidence by Month (perceived and recorded) and Seasonality}

Household inhabitants differed in their perception of gastrointestinal and respiratory disease by month. As observed in Figure 6a, respiratory diseases are perceived to be more frequent in the dry season, whereas gastrointestinal disease are perceived as more common during the rainy season. Figure $7 \mathrm{~b}$ shows how households identify seasons by month. The perceived seasonality Figure $7 \mathrm{~b}$ corresponds somewhat to the perceived disease in Figure 7a, as households tend to associate diseases 
with climate. For example, over $60 \%$ of the households identify April to August as months with more diarrheal disease. These months were also considered as the last part of the warm dry season and 'rainy', and the interviewed people tended to mention the heat and rain as a cause of the disease. Similarly, November to February were considered months with higher respiratory disease and were also identified as 'cold dry' months. The perception of diarrheal and respiratory diseases is similar but not equal to the recorded disease data obtained from the epidemiological register from 2014 to 2017 that show that the number of cases of ADDs is high from May to August, and the number of cases with Acute Respiratory Disease (ARD) is high between October and February (Figure 8).

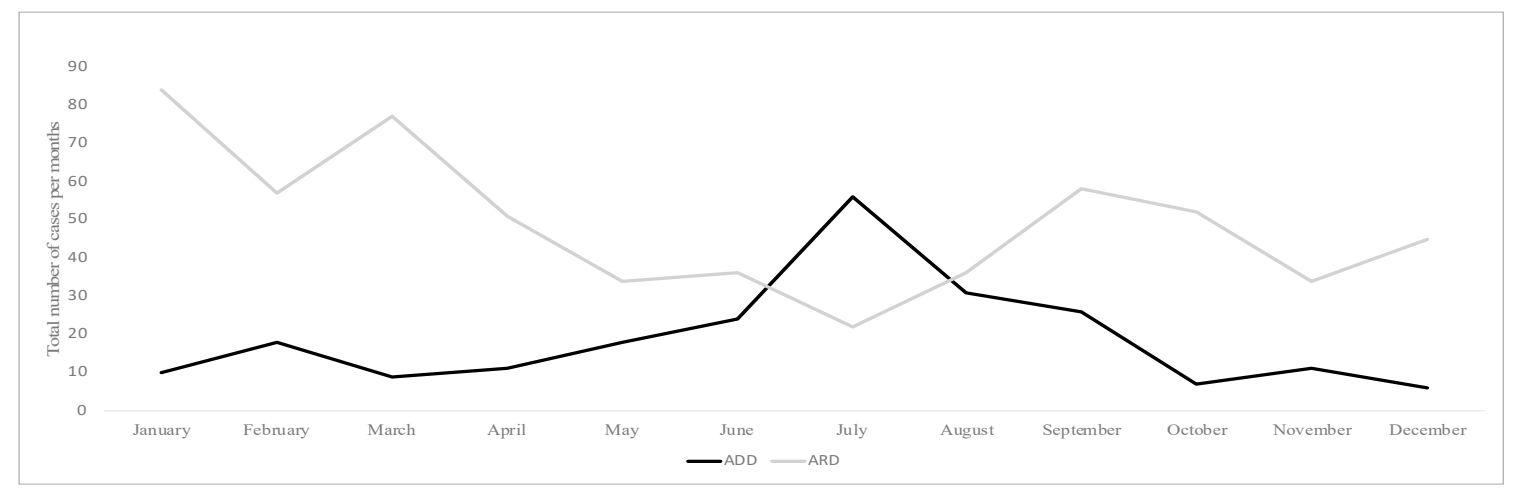

Figure 8. Acute Diarrheal Diseases (ADDs) and Acute Respiratory Disease (ARD) recorded by month 2014-2017.

Additionally, households identified various rituals related to water and agriculture. In the season where the corn is planted (the first rainy), it is believed that the corn needs the energy from the children to grow, and the deer (a sacred animal) jumps on the growing corn plant. At that time, children become sick and lose weight, and this disease is called "deer jumping diseases".

\subsubsection{Perceptions of Causes and Origins of Disease}

There are different views of the cause of diseases and understanding the perception that these communities have regarding the causes and consequences of disease is deeply complex. The interviews reflected what has been observed in other studies: that the relationship of cause with diseases is related to the community's worldview [25]. In this case, disease is a result of disrespecting gods, by not performing rituals or performing them incorrectly, or the gods heal the members of the family and they must be paid with offerings. For example, in one household interview, the mother indicated that their lack of performing a cow sacrifice led to their children getting sick with diarrhea for over a month, and that the medicine that the doctor gave them would not cure them until they sacrificed a calf in the maize field.

Although the concept of well-being is very similar to the Western concept of health, the state of imbalance differs from the Western notion of disease. It is believed that when the gods are not treated correctly (for not complying with el costumbre), this imbalance manifests magically by introducing strange objects to the body (stones or other objects) that, during the healing rites, must be extracted from the bodies of the patients by the traditional doctor (marakate). Several topics cannot be explained in detail; however, it is important to take into account the importance of el costumbre (the religious cosmovision of the Wixaritari), which is based on the notion of very close and direct reciprocal relationships between people and nature.

\subsubsection{Household Hygiene Practices and Sanitation}

The issue of hygiene was not generally perceived to be related to disease incidence and water management, according to the interviews. The average number of bath days per week is 2.4. Fifty-two percent of households responded that they wash their hands before eating and only $8 \%$ responded that 
they wash their hands after going to defecate. Households tended to answer questions according to the instructions given to them by health professionals in the community and by an educational program conducted by the Ha Ta Tukari organization, which includes a school workshop that shows the need for a full body bath "every three days" and washing of hands "before eating". Indeed, 96\% of households do not have bathrooms (plumbing) or latrines, and open defecation is a common practice. Garbage disposal was similar in all households; $72 \%$ reported burning part of the garbage near the houses.

According to the results presented above, we observed an association between RWHSs and lower gastrointestinal disease rates and higher water quality. However, household perceptions do not necessarily reflect this observation. Based on household interviews, we created a two-belief typology: 1. Belief that climate is causing disease and; 2 . Belief that rituals (or absence of) are causing or healing the disease. Sixty-four percent of interviewees in households perceived typology number 1 , $16 \%$ perceived typology number 2 , and $20 \%$ answered that they do not know the cause of disease. Typology number 2 was not evident at first but after longer discussions and open-ended questions, the importance of rituals became evident in many interviews. In the majority of cases, hygiene was not seen by households as related to disease incidence. Therefore, there is a disconnect between the impact of RWHSs (water quantity and quality) and the way that many households in this indigenous community understand the way that disease is transmitted and its relationship to water.

\section{Discussion}

\subsection{The Potential for RWHSs to Improve Water Quantity and Quality in Indigenous Rural Communities}

Water scarcity (quantity and quality) differentially affects the poorest and most vulnerable populations. For example, there are 370 million indigenous people across the world and a vast majority still live in isolated areas where environmental conditions are harsh and access to basic services is rare $[33,34]$. Their access to health services is usually lower, their health status is usually poorer, and health-related data for these populations remains incomplete, inaccurate, or absent [35]. The health situation of indigenous communities is in substantial disadvantage compared with non-indigenous people in Mexico. One of the main consequences of water stress faced by the Wixarika communities is a high incidence of gastrointestinal and skin disease [28,36]. In this community, the access to water over the last four years has changed with the implementation and adoption of RWHSs, and the results of this analysis show that water access through this technology is associated with improved water quality, quantity, and a reduction in the incidence of gastrointestinal disease.

The use of rainwater to solve a water scarcity problem is not new and has been considered a valid option, especially in isolated rural contexts where infrastructure is limited [16,37-39]. The understanding of the consequences of the implementation of these systems has been studied, but the evidence of the benefits is still scarce $[17,40]$. To address water scarcity, this community has been diversifying their water sources over the last four years, including with RWHSs. At present, there is a diversity of water sources, which reflect a process of adaptation to water scarcity. The variation and use of water sources change throughout the year, primarily because the access changes throughout the different seasons. The understanding of the context in this study is essential because the costumes or el costumbre has a broad influence on all the aspects of their lives (including health and even scarcity of water). The strategies to address problems such as water scarcity or diarrhea in children are unlikely to be effective without an understanding of the household perception of health problems associated with water. For example, although water quality in the samples was better when water came from rainwater capture, there was still a presence of Coliforms, which means that the management of water (i.e., storage procedures) is also imperative for increasing water quality. The presence of $E$. coli in high levels ( $>1000 \mathrm{CFU}$ ) in water that is used to drink is very important because E. coli is considered a pathogenic bacterium and the main cause of gastrointestinal diseases [41]. The health and well-being of local communities and ecosystems will need a deeper understanding of the local context and will need 
to address current and future human-environmental challenges depending on the active involvement of all water users [10].

\subsection{Implications for Sustainable Development}

Ecotechnologies have been touted as a potential solution to meet the needs of marginalized communities, often in rural contexts. The collection of rainwater appears to be a viable alternative to solve problems of scarcity and water quality in isolated communities. However, these technologies not only operate in tangible terms (i.e., access to basic services), but they also interact with culture and customs of the communities as well as households where they are implemented. The results of this study show that RWHSs do have an impact on water quantity and quality and on the incidence of gastrointestinal illness. However, the presence of these systems does not control other factors such as the storage and use of other sources of water-nor do they control for hygiene practices and how households perceive the link between health and water quality.

Diarrheal disease is the second leading cause of death in children under five years old. A significant proportion of diarrheal disease can be prevented through safe drinking water and adequate sanitation and hygiene [11,41]. Shifts in perception and behavior related to water use and hygiene are complex and these require understanding diverse cosmovisions that dictate behavior in indigenous communities. Consequently, what is initially a technological fix to a problem of basic needs becomes a potential step in modifying customs and habits within households and communities and a step towards sustainable development from the Western point of view. The idea that health is related to the behavior of individuals and households is not part of the cosmovision of this community, so increased water quantity and quality can only go so far in modifying health issues in the communities. But to what extent should ecotechnologies shift culture in specific contexts? Is it desirable to move cosmovision towards a Western view of cause-consequence in the name of sustainable development? These are questions that are difficult to answer but are linked to the desire to meet the sustainable development goals. Although the findings of this study are restricted to a single study case, many other communities in the region and in Mexico live under similar conditions to the inhabitants of La Laguna. A fully inclusive collaboration, both horizontally and vertically, is required to create a more feasible balance between national and international goals [10].

\section{Conclusions}

This study examined the impacts of RWHSs and the potential of this eco-technology as a viable option for solving water stress in very isolated communities, while taking into account household perceptions of the relationship between access to water and health. The findings suggest that the reduction of the incidence of cases of acute diarrheal disease is associated with improvement in access to water quantity and quality. However, the perceptions of the households about health issues throughout the year were generally not related to water access. Although higher quality drinking water can produce a change in the incidence of cases of diarrhea in children, sanitation and hygiene were not seen by the households as linked to health in the community under investigation, which could have a relevant health impact.

In an isolated, but ever changing social-ecological system, focusing only on the impacts of water access may serve to ignore the context in which interventions occur. In order to improve access to water in isolated and indigenous communities, it is imperative to consider the local context and culture. Future research is needed to understand how addressing a specific goal such as improving water access can produce deeper changes in other aspects of life in specific contexts of the Global South. For example, increased access to water could potentially allow more time dedicated to other activities in a household, but at the same time could limit water-collection activities that provide a shared space for women. Work with indigenous people requires a more systematic and holistic understanding through which water interventions operate. 
As our findings suggest, traditional measures of development and progress like those outlined in the Sustainable Development Goals-access to water, sanitation, electricity, Western health and medicine-may not indicate 'progress' or development to some of the Wixaritari people. As mentioned by Carrasco Henríquez et al. (2009), development indicators, even though they reflect new ways of understanding development and are intended to involve communities, are still limited to quantitative data (literacy, poverty, longevity, birth rate or access to water, etc.), and make the qualification of the actors invisible while measuring the success or failure of sustainable development projects [42]. Drawing on our findings in this case study, we argue that, in terms of water access, different scales (sustainable well-being from local, regional to global) and perceptions should be considered in order to meet the ambitious Sustainable Development Goals, specifically SDG number 6.

Author Contributions: Conceptualization, S.K.G.-P.; Investigation, S.K.G.-P.; Supervision, A.M.L. and M.M.-H.; Writing—original draft, S.K.G.-P.; Writing—review and editing, A.M.L. and M.M.-H.

Funding: This research received no external funding.

Acknowledgments: This paper would not have been possible without the families in the La Laguna community and the Wixaritari people. Special thanks to physician Claudio Alejandro Alejo Pérez for all his work collecting the epidemiological data that were used in this research, Matias C. Baranzelli for help on the epidemiological data analysis, to Lakshmi Charli Joseph and Elizabeth Tellman for help and support in part of the fieldwork and Leticia Merino Pérez for advice on methodological design. We acknowledge the support and contributions of the all members of the project Ha Ta Tukari ('water, our life'), especially Enrique Lomnitz Climent for the accompaniment in the fieldwork. We thank Consejo Nacional de Ciencia y Tecnología (CONACyT, Mexico) for offering the doctoral scholarship to SKGP (No. 421723). The first author gratefully acknowledges the Program in Sustainability Sciences, UNAM (Posgrado en Ciencias de la Sostenibilidad, Universidad Nacional Autónoma de México), Mexico.

Conflicts of Interest: The authors declare no conflict of interest.

\section{References}

1. Murthy, S.L. The Human Right to Water and Sanitation: History, Meaning, and the Controversy Over-Privatization. Berkley J. Int. Law 2013, 31, 89-149. [CrossRef]

2. UN. Transforming Our World: The 2030 Agenda for Sustainable Development; United Nations General Assembly: New York, NY, USA, 2015; pp. 1-35.

3. WWF. Final Report of the 5th World Water Forum. Available online: http://www.Royalcommission.Vic.Gov. Au/Finaldocuments/Summary/Pf/Vbrc_Summary_Pf.Pdf (accessed on 26 August 2006).

4. CONAGUA. Estadísticas del Agua en México; Comisión Nacional del Agua: Mexico City, Mexico, 2011.

5. Murtinho, F.; Tague, C.; de Bievre, B.; Eakin, H.; Lopez-Carr, D. Water Scarcity in the Andes: A Comparison of Local Perceptions and Observed Climate, Land Use and Socioeconomic Changes. Hum. Ecol. 2013, 41, 667-681. [CrossRef]

6. Sullivan, C. Calculating a Water Poverty Index. World Dev. 2002, 7, 1195-1210. [CrossRef]

7. Rijsberman, F.R. Water Scarcity: Fact or Fiction? Agric. Water Manag. 2006, 80, 5-22. [CrossRef]

8. UN-Water. Financing Universal Water, Sanitation and Hygiene under the Sustainable Development Goals: Global Analysis and Assessment of Sanitation and Drinking-Water (GLAAS) 2017 Report; UN-Water: Geneva, Switzerland, 2017.

9. Assmus, G.C. Agua, Pobreza y Equidad: Un Análisis Asimétrico. Rev. Latinoam. Bioet. 2015, 15, 90-99. [CrossRef]

10. Johnston, B.R.; Strang, V. Water, Cultural Diversity, and Global Environmental Change: Emerging Trends, Sustainable Futures; UNESCO-IHP: Paris, France, 2012; p. 253. [CrossRef]

11. Moe, C.L.; Rheingans, R.D. Global Challenges in Water, Sanitation and Health. J. Water Health 2006, 4, 41-58. [CrossRef] [PubMed]

12. Amos, C.C.; Rahman, A.; Gathenya, J.M. Economic Analysis and Feasibility of Rainwater Harvesting Systems in Urban and Peri-Urban Environments: A Review of the Global Situation with a Special Focus on Australia and Kenya. Water 2016, 8. [CrossRef]

13. Ímaz Gispert, M.; Armienta Hernández, M.A.; Lomnitz Climent, E.; Torregrosa Flores, M.F. Rainwater Harvesting as a Drinking Water Option for Mexico City. Sustainability 2018, 10, 3890. [CrossRef] 
14. Tanner, T.; Lewis, D.; Wrathall, D.; Bronen, R.; Cradock-Henry, N.; Huq, S.; Lawless, C.; Nawrotzki, R.; Prasad, V.; Rahman, M.A.; et al. Livelihood Resilience in the Face of Climate Change. Nat. Clim. Chang. 2014, 5. [CrossRef]

15. Fonseca, J.E.; Carneiro, M.; Pena, J.L.; Colosimo, E.A.; da Silva, N.B.; da Costa, A.G.F.C.; Moreira, L.E.; Cairncross, S.; Heller, L. Reducing Occurrence of Giardia Duodenalis in Children Living in Semiarid Regions: Impact of a Large Scale Rainwater Harvesting Initiative. PLoS Negl. Trop. Dis. 2014, 8. [CrossRef]

16. Jonathan, D.; Paul, R.H. Risk of Gastrointestinal Illness Associated with the Consumption of Rainwater: A Systematic Review. Environ. Sci. Technol. 2012, 46, 2501-2507.

17. Williams, E. Huichol Ethnography and Archaeological Interpretation. Pap. Inst. Archaeol. 1990, 6-15. [CrossRef]

18. CONAPO. La Marginación En Los Municipios. Índice Marginación Por Entid. Fed. Y Munic. 2015, 2015, 23-38. [CrossRef]

19. De la Torre, R. Ten Years of the Human Development Index in Mexico. Real. Datos Espac. 2012, 3, 149-163.

20. Neurath, J.; Pacheco Bribiesca, R.C. Atlas de Culturas Del Agua En América Latina y El Caribe. In Pueblos Indígenas De México Y Agua: Huicholes (Wixarika); Instituto Mexicano de Tecnología del Agua: Mexico City, Mexico, 2006; pp. 1-53.

21. Liffman, P.M. Huichol Territory and the Mexican Nation: Indigenous Ritual, Land Conflict, and Sovereignty Claims; University of Arizona Press: Tucson, AZ, USA, 2011.

22. Sánchez Domínguez-Guilarte, M. Los Wixaritari a Través de La Antropologia, La Historia y La Literatura: La Construcción y Popularización de Un Estereotipo. Front. Rev. História 2016, 18, 51-75.

23. Neurath, J. Ambivalencias Del Poder y Del Don En El Sistema Político Ritual Wixárika. In Los pueblos amerindios más allá del Estado; México Universidad Nacional Autónoma de México, Instituto de Investigaciones Históricas: Mexico City, Mexico, 2011.

24. Torres, G. La Fuerza del Costumbre. Un Acercamiento a la Realidad Tlapaneca (Me'Phaa). Bachelor's Thesis, Etnohistoria, Escuela Nacional de Antropología e Historia, Mexico City, Mexico, 2014; p. 102.

25. Verdín Amaro, K.I.; García, S.S. Red Semántica de Las Enfermedades Del Pueblo Wixárika o Huichol. Alteridades 2012, 22, 97-110.

26. Takeuchi, K.; Osamu, S.; Lahoti, S.; Gondor, D. Growing up: 10 Years of Publishing Sustainability Science Research. Sustain. Sci. 2017. [CrossRef]

27. UN-Water. Water for a Sustainable World; UN-Water: Geneva, Switzerland, 2015. [CrossRef]

28. Johnson, J.T.; Howitt, R.; Cajete, G.; Berkes, F.; Louis, R.P.; Kliskey, A. Weaving Indigenous and Sustainability Sciences to Diversify Our Methods. Sustain. Sci. 2016, 11, 1-11. [CrossRef]

29. Franquesa-Soler, M.; Sandoval-Rivera, J.C.A. Mentoring Program to Achieve SDGs in Local Contexts: A Case Study in Communities from Southern Mexico. Sustain. J. Rec. 2019, 12, 109-114. [CrossRef]

30. Barrera, R.O. Consideraciones Geomorfológías Sobre La Sierra Madre Occidental En El Norte de Jalisco, México Geomorphological Considerations about the Sierra Madre Occidental in Northern Jalisco. Investig. Geográficas 2002, 48, 44-75.

31. Santo Domingo, A.F.; Castro-Díaz, L.; González-Uribe, C.; The Wayúu Community of Marbacella; The Barí Community of Karikachaboquira. Ecosystem Research Experience with Two Indigenous Communities of Colombia: The Ecohealth Calendar as a Participatory and Innovative Methodological Tool. Ecohealth 2016, 13, 687-697. [CrossRef] [PubMed]

32. Levy, K.; Nelson, K.L.; Hubbard, A.; Eisenberg, J.N.S. Rethinking Indicators of Microbial Drinking Water Quality for Health Studies in Tropical Developing Countries: Case Study in Northern Coastal Ecuador. Am. J. Trop. Med. Hyg. 2012, 86, 499-507. [CrossRef] [PubMed]

33. Gracey, M.; King, M. Indigenous Health Part 1: Determinants and Disease Patterns. Lancet 2009, 374, 65-75. [CrossRef]

34. UN. State of the World's Indigenous People; UN: New York, NY, USA, 2009; p. 250.

35. Ghebreyesus, T.A. Improving the Health of Indigenous People Globally. Lancet Oncol. 2018, 19 , e277. [CrossRef]

36. Guevara, Y.; De Haro, I.; Cabrera, M.; García De La Torre, G.; Salazar-Schettino, P.M. Enteroparasitosis En Poblaciones Indígenas y Mestizas de La Sierra de Nayarit, México. Parasitol. Latinoam. 2003, 58, 30-34. [CrossRef] 
37. Adler, I.; Hudson-Edwards, K.A.; Campos, L. Converting Rain into Drinking Water: Quality Issues and Technological Advances. Water Sci. Technol. Water Supply 2011, 11, 659-667. [CrossRef]

38. Rahman, S.; Khan, M.T.R.; Akib, S.; Din, N.B.C.; Biswas, S.K.; Shirazi, S.M. Sustainability of Rainwater Harvesting System in Terms of Water Quality. Sci. World J. 2014, 2014. [CrossRef]

39. Jin, Y.Z.; Zhou, L.W.; Lo, K.F.A. Optimum Matching Model Using Long-Term Computing on Safer Rural Domestic Water Supply Based on Rainwater Harvesting. Int. J. Environ. Res. Public Health 2018, 15. [CrossRef]

40. Campisano, A.; Butler, D.; Ward, S.; Burns, M.J.; Friedler, E.; DeBusk, K.; Fisher-Jeffes, L.N.; Ghisi, E.; Rahman, A.; Furumai, H.; et al. Urban Rainwater Harvesting Systems: Research, Implementation and Future Perspectives. Water Res. 2017, 115, 195-209. [CrossRef]

41. Gorchev, H.G.; Ozolins, G. WHO Guidelines for Drinking-Water Quality. WHO Chron. 1984, 38, $104-108$. [CrossRef]

42. Carrasco Henríquez, N.; Samaniego Sastre, M.; Durán Pérez, T. Indicadores de desarrollo? Alcances antropológicos en torno a los procesos de medición y control del desarrollo social y cultural. Pública Gestión Estatal 2009, 9, 59-72. [CrossRef]

(C) 2019 by the authors. Licensee MDPI, Basel, Switzerland. This article is an open access article distributed under the terms and conditions of the Creative Commons Attribution (CC BY) license (http://creativecommons.org/licenses/by/4.0/). 